\title{
Esfera de Reprodução em uma Visão Masculina: Considerações sobre a Articulação da Produção e da Reprodução, de Classe e de Gênero*
}

KAREN GIFFIN **

$\mathrm{Na}$ análise da condição feminina, desde a década de 60 os trabalhos estabeleceram como conceito mais abrangente a divisão sexual do trabalho e dentro dela a estruturação das atividades de produção e de reprodução.

Variações na organização e articulação de estruturas de produção e reprodução resultam em diferenças na situação da mulher através do tempo e entre grupos e classes sociais. Apesar disto, a designação muito geral de responsabilidades, segundo o gênero, foi refletida e cristalizada no plano social em estereótipos sexuais que encobriam e mascaravam as exceções: o homem, responsável pelo sustento econômico da família, é também o -sujeito histórico cuja atividade sexual é valorizada fora do contexto reprodutivo, embora o número de filhos mostre sua virilidade; a mulher, responsável pelo lar, é também o objeto histórico cuja atividade sexual é legitimada apenas na reprodução dos filhos legítimos.

$\mathrm{Na}$ esfera da família como instituição histórica, a passagem da família "tradicional" para a "moderna" é pautada por transformações geradas pelos

* Trabalho realizado com o apoio do PARES/ENSP, submetido para publicação em outubro de 1991. Lucia Baptista foi responsável pela dinâmica de grupo; Gilson Alves de Jesus, Carlos Correia de Meireles, Genaro da Silva Virgílio e Marcos Salvador Malaquias Pinheiro formaram a equipe de entrevistadores.

** Socióloga, professora visitante do Departamento de Ciências Sociais e Coordenadora da área temática “Gênero e Saúde” no Doutorado e Mestrado em Saúde Pública, ENSP/Fiocruz. 
processos de industrialização e urbanização que resultaram na perda de funções produtivas antes realizadas no plano familiar. Mantendo suas funções de reprodução biológica e social, a família moderna é caracterizada pelas teorias funcionalistas como entidade predominantemente "socioemocional", enquanto a ótica marxista aponta o seu papel na reprodução da força de trabalho.

Ao interior da família, análise desde a perspectiva de gênero promove investigação dos conflitos de interesse entre homens e mulheres, e enfatiza. o fato de a família, como instituição social, articular instâncias tanto ideológicas como materiais, estando sujeita a refletir contradições entre ambas. Aponta a "invisibilidade social" do trabalho produtivo da mulher e a necessidade, na análise da condição feminina, de se levar em conta tanto sua real inserção nas atividades produtivas como a articulação variada desta esfera com a esfera reprodutiva.

Na década de 70, o conceito "estratégias de sobrevivência" ganha prevalência nas análises de famílias de baixa renda na América Latina, principalmente nas áreas urbanas "periféricas" onde a inserção "informal" no mercado de trabalho urbano resulta na ocupação "informal" dos espaços urbanos sem infra-estrutura, fenômeno crescentemente visível com a massiva migração da época.

Nessas análises, a tentativa de entender "como sobrevivem os marginados" aponta as redes de reciprocidade entre famílias pobres que organizam trocas de bens e serviços que ajudam a garantir a sobrevivência. ${ }^{1} \mathrm{~A}$ organização interna dessas famílias, por sua vez, é caracterizada pela incorporação de membros além do núcleo pais e filhos, pela geração de renda feminina no âmbito familiar e por taxas de fecundidade mais altas que nos outros segmentos sociais. ${ }^{2}$

Desde essa ética conceitual, o número maior de filhos nas famílias mais pobres é interpretado como vantagem econômica, no sentido de significar mais elementos potenciais para a bủsca de renda. ${ }^{3}$ Esta interpretação, às vezes presente nas representações das mães de baixa renda como "seguran-

1. Ver o clássico L. A. de Lomnitz, Como Sobreviven los Marginados, México, Siglo Veintiuno, 1975.

2. A. Flisfisch, "Estructura Social: Particularidades Contextuales y Comportamiento Reproductivo Urbano y Rural”, in PISPAL, Urbanización, Estructura Urbana y Dinámica de Población, Santiago, PISPAL, 1977.

3. M. Giminez, "Population and Capitalism”, Latin American Perspectives, vol. 4, 1977, p. 4; Z. Machado Neto, Mulher, Dimensāo de Existência/Dimensāo de Sobrevivência: Um Estudo de Caso com Mulheres Faveladas, I ${ }^{\circledR}$ Simpósio Mexicano-Centroamericano de Investigaciones sobre la Mujer, México, 1977; K. Woortmann, Family Planning among Peasants and the Urban Poor, s.d., mimeo. 
ça na velhice", é inteiramente coerente com o estereótipo histórico da mulher reprodutora, o que certamente facilitou sua incorporação conceitual como elemento explicativo do comportamento reprodutivo desses segmentos, assim como aparentemente revelou a base material que sustenta a manutenção da ideologia tradicional que caracteriza a mulher como essencialmente mãe, e não como trabalhadora.

Todavia, dados relativos à cidade do Rio de Janeiro, gerados por estudo sobre fecundidade organizado pelo Centro Latino-Americano de Demografia - Celade em sete cidades latino-americanas, mostram que, ainda em 1963-64, as hipóteses advindas da clássica transição demográfica são postas em xeque pela realidade empírica: a partir de uma amostra de mulheres casadas considerada representativa de todas as classes, os dados evidenciam que a taxa de fecundidade no Rio de Janeiro foi mais baixa do que o esperado, considerando o nível de uso de contraceptivos e de desenvolvimento socioeconômico. ${ }^{4}$

Outras análises dessa base de dados revelam o aborto como método importante de controle da fecundidade ${ }^{5}$ e a esterilização como opção de $6,6 \%$ das usuárias, mais empregada pela classe alta ( $8 \%$ das usuárias) do que pela classe baixa $(5,3 \%) .{ }^{6} \mathrm{O}$ trabalho de Iutaka refere-se, ainda, a uma taxa de uso de métodos contraceptivos de $74 \%$ na classe alta, $67 \%$ na classe média e $49,7 \%$ na classe baixa, surpreendentemente parecidas com as taxas atuais.

Dentre todas as cidades pesquisadas, a amostra do Rio de Janeiro (juntamente com a de Buenos Aires) foi a que apresentou o maior grau de aprovação, pelas mulheres casadas entrevistadas, do trabalho feminino remunerado: $82-84 \%$ na classe média e $70 \%$ do total da amostra. ${ }^{7}$ Outros estudos apontam que a diferença de fecundidade entre os três estratos sociais era pequena, sugerindo a necessidade de reformulação da hipótese do valor econômico dos filhos ${ }^{8}$ e, mais surpreendente ainda, que o tamanho ideal de família era menor nas famílias de classe baixa. ${ }^{9}$

4. P. Hass, "Maternal Role Incompatibility and Fertility in Urban Latin America", Journal of Social Issues, vol. 28, $\mathrm{n}^{\circ} 2,1972$, pp. 111-27.

5. B. Hutchinson, "Induced Abortion in Brazilian Married Women",América Latina, vol. 7, $\mathrm{n}^{2}$ 4, 1964, p. 21.

6. S. Iutaka, “A Estratificaçăo Social e o Uso Diferencial de Métodos Anticoncepcionais no Brasil Urbano”, América Latina, $\mathrm{n}^{2} 8,1965$, pp. 101-19.

7. P. Hass, “Maternal Role...”, op. cit.

8. S. Iutaka, "Factores Relacionados con la Fecundidad de las Mujeres en Rio de Janeiro", Anais de la Conferencia Regional Latinoamericana de Población, Santiago, 1972, pp. 329-33.

9. B. Hutchinson, “Induced Abortion...”, op. cit. 
Com a crise econômica dos anos 80 , novos fatos se impõem às interpretações. Em primeiro plano, junto com o aprofundamento da desigualdade na distribuição de renda e a regressão marcada do poder de consumo das classes trabalhadoras, destaca-se a entrada maciça da mulher no mercado de trabalho e a queda brusca da taxa de fecundidade em todas as regiōes, classes e faixas etárias no Brasil. ${ }^{10}$

Paralelamente ao fenômeno da dupla jornada de trabalho, que implica uma contradição entre o papel produtivo e reprodutivo da mulher, observase que crianças e jovens de 10 a 17 anos também estão ocupados em atividades de geração de renda fora do domicílio,11 e que a categoria "mulher chefe de família" cresce constantemente. ${ }^{12}$

Evidencia-se não só a dependência da família na renda monetária, mas também as contradições presentes nas estratégias de sobrevivência daquelas mais pobres: a oferta ampliada de mão-de-obra nas atividades "informais" serve para diminuir os ganhos de cada um; a ocupação dos espaços urbanos sem infra-estrutura adequada é um risco à saúde; a necessidade de cuidados com os filhos menores e a falta de creches nem sempre impedem a ausência da mãe que sai em busca de renda; e o trabalho infantil precoce, indispensável à sobrevivência imediata, dificulta a escolarização, que é necessária, embora não suficiente, à criação de condições futuras melhores. ${ }^{13}$

Considerando a reprodução da força de trabalho na sociedade como todo, a busca de renda pelas mulheres pobres garante a oferta de mão-de-obra barata nos serviços domésticos (ainda em 1980, 20\% da força de trabalho feminina dedicava-se a esta ocupação), o que facilita o trabalho remunerado da mulher empregadora, e que, por sua vez, ajuda a garantir a escolarização dos filhos destas e suas vantagens relativas como força de trabalho futura.

Embora as mulheres, na sua quase totalidade, continuem a ter filhos, a contracepção e/ou o aborto passam a ser adotados pela grande maioria, fato explicado por elas como função das dificuldades econômicas. ${ }^{14}$ Isto pode

10. C. Simões, “As Características Demográficas do Recente Declínio da Fecundidade e o Papel da Auto-Regulaçāo e do Planejamento Familiar”, in IBGE/Unicef, Perfil Estatístico de Crianças e Mães no Brasil: A Situação da Fecundidade, Rio de Janeiro, IBGE/Unicef, 1988.

11. R. R. Lima e F. Burger, “O Menor e o Mercado de Trabalho no Brasil: Da Crise ao Cruzado”, in J. P. Chahad e R. Cervini, eds., Crise e Infância no Brasil, São Paulo, Unicef, 1988.

12. Fiocruz, “A Mulher Brasileira: Estatísticas de Saúde”, Dados 10, Fiocruz, 1986.

13. K. M. Giffin, “A Mulher, a Cidade e os Programas Sociais”, in Mulher e Politicas Públicas, Rio de Janeiro, IBAM/Unicef, 1991.

14. D. Valladares, S. Sanchez e K. Giffin, Mulheres, Participação e Saúde: Uma Experiência, Rio de Janeiro, Flacso/Unicef, 1987. 
ser entendido tanto em termos do custo de sustentação dos filhos como em termos da necessidade de elas trabalharem fora.

Certas mudanças no papel feminino são evidenciadas por indicadores que dependem relativamente pouco da dimensão interpretativa dos indivíduos (taxa de fecundidade, taxa de participação na População Economicamente Ativa - PEA). O fato de a família ainda em 1980 ser uma instância mediadora da participação feminina na PEA é também refletido nas taxas femininas específicas por estado civil. Faltam ainda os dados censitários de 1991 que mostrarão se, e até que ponto, este fato está mudando, mas existem dados de outros casos nacionais de estancamento econômico que mostram que, nesta situação, nem a idade, nem o estado civil, nem a fertilidade impedem as atividades femininas. ${ }^{15}$

Quanto às representaçōes sociais, alguns estudos mais recentes sobre a mulher de baixa renda no Brasil concluem que os estereótipos sexuais tradicionais se mantêm neste segmento da população, ${ }^{16}$ enquanto outras análises sugerem que a mulher aceita ou rejeita o papel doméstico, dependendo das alternativas que ela tem de trabalho remunerado, ${ }^{17} \mathrm{e}$ ainda outros autores apontam que, mesmo na classe média, onde as oportunidades de trabalho feminino são mais interessantes e os estereótipos estão sendo questionados, a mulher continua "sobrecarregada com as velhas representações". ${ }^{18}$

Eunice Durham, em dissonância, argumenta que a valorização da família e do papel doméstico da mulher nas classes trabalhadoras, se analisada sob a ótica da sua inserção nas práticas sociais, não aparece como um "irracional apego ao passado", mas sim como "bandeira de legitimação da luta por salários mais altos”, já que o trabalho remunerado da mulher dessa classe é resultado da pobreza e gera uma dupla jornada (doméstica, em muitos casos) das mais desgastantes. ${ }^{19}$

15. N. Aguiar, “Mulheres na Força de Trabalho na América Latina: Um Ensaio Bibliográfico”, $B I B, \mathrm{n}^{\circ} 16,1983$, pp. $25-43$.

16. T. Salem, "Mulheres Faveladas: Com a Venda nos Olhos",Perspectivas Antropológicas da Mulher, Rio de Janeiro, Zahar, 1980.

17. J. R. Prandi, "A Mulher e o Papel de Dona de Casa: Representaçōes e Estereótipos", Revista de Antropologia, vol. 24, 1981, pp. 109-21; Z. A. Farias, Domesticidade: "Cativeiro" Feminino?, Rio de Janeiro, Achiamé, 1983.

18. M. T. Luz, "Identidade Masculino-Feminino na Sociedade Urbana Brasileira Atual: Crise nas Representaçōes", in C. de Poián, org., Homem-Mulher: Abordagens Sociais e Psicanalíticas, Rio de Janeiro, Taurus, 1987.

19. E. Durham, "A Família Operária: Consciência e Ideologia”,Revista de Ciências Sociais, vol. $23, n^{2} 2,1980$, pp. 201-13. 
Com este argumento, abre-se uma grande indagação com respeito ao sentido da proibição masculina do trabalho feminino por parte dos maridos trabalhadores, reportada e discutida em alguns estudos. ${ }^{20}$ No de Macedo, baseado em dados de 1974, 51\% dos maridos aceitam o trabalho da mulher apenas quando definido como necessário, mas, neste caso, é visto como obrigação. Esta necessidade qualifica consideravelmente, mas não suplanta, a definição tradicional do papel da mulher, já que “[...] uma vez superadas as dificuldades do momento, deverá ser possível que cada um reassuma suas verdadeiras funções". ${ }^{21}$

Igualmente, porém, $51 \%$ dos maridos "acham que as filhas têm tanta obrigação de trabalhar quanto os filhos”, 22 o que indica que a nova geração já estava sendo preparada para um papel mais abrangente, e não em função da ideologia de igualdade sexual, mas sim pela situação concreta vivida.

De qualquer maneira, é evidente que as grandes transformações que vêm se esboçando foram aprofundadas na última década, assim como foi ampliado o abismo entre o ideal da mulher dedicada exclusivamente ao lar e aos numerosos filhos, e a realidade econômica das famílias de baixa renda.

Começam a aparecer análises, baseadas na lógica da subordinação da reprodução à produção e nos dados demográficos, que apontam a transformação do filho - antes, um recurso produtivo da família - em obstáculo ao necessário trabalho remunerado da mulher. ${ }^{23}$ Mesmo com respeito à influência da ideologia dos papéis femininos nas representações dos segmentos sociais, é necessário reconhecer que, no início da década de 90, alguma versão da ideologia feminista já circula na sociedade brasileira, oferecendo uma nova representação da mulher, mais compatível com as novas práticas sociais. Só que, como argumentam faz tempo as feministas, a atribuição histórica de responsabilidades da esfera reprodutiva à mulher não impede que ela assuma, também, o encargo de trabalho remunerado fora do lar.

Já tendo reconhecido que a coerência entre as instâncias ideológica e material da família é relativa, encobrindo às vezes grandes contradições,

20. A. M. Rodrigues, Operário, Operária, Sāo Paulo, Símbolo, 1978; C. C. Macedo, A Reprodução da Desigualdade, São Paulo, Hucitec, 1979.

21. C. C. Macedo, A Reprodução da..., op. cit.

22. Idem.

23. K. M. Giffin, "Nosso Corpo nos Pertence: A Dialética do Biológico e do Social”, Cadernos de Saúde Pública, vol. VII, n² 2, 1991, pp. 190-200; M. V. J. Pena, “Política e Populaçāo: Dados sobre um Estado de Duas Caras”, Physis, vol. 1, n² 1, 1991, pp. 97-116. 
apontamos também a necessária consideração de que, se os dados nacionais indicam mudanças nas práticas sociais de trabalho e fecundidade feminina, e os estudos das famílias mostram ambigüidades ideológicas correlatas, as mudanças nos papéis e representações masculinos são ainda para serem buscadas, certamente, em parte pela força dos velhos estereótipos, junto aos(às) pesquisadores(as). Ou seja, a relativa ausência de dados sobre a experiência e a visão masculinas com referência às questões da esfera reprodutiva é mais do que coerente com o estereótipo que relega à mulher, somente, essas responsabilidades. Em face disto, os dados a seguir pretendem contribuir para superar os estereótipos sexuais no que diz respeito à definição dos objetos de pesquisa e, quanto ao conteúdo, iniciar uma investigação de possíveis mudanças nas representações que refletem as transformações materiais.

\section{Metodologia}

Os dados foram gerados a partir de uma metodologia de pesquisa participativa que incorporou quatro jovens homens das favelas de Manguinhos Zona Norte da cidade do Rio de Janeiro - no processo de desenvolvimento do instrumento e coleta de dados. Neste processo, que durou seis meses a partir de outubro de 1989, três meses foram dedicados à formação e preparação do grupo, que se reuniu duas vezes por semana durante esse período. A partir de um exercício de representação em forma de colagem do "mundo masculino" e do "mundo feminino", feito pelos futuros entrevistadores, o trabalho em grupo baseou-se na troca de experiências que permitiu a todos perceberem as semelhanças e diferenças existentes entre si. Ênfase foi dada à legitimidade de as pessoas terem maneiras diferentes de viver, perceber, expressar e valorizar suas experiências, o que foi considerado como fundamental, tanto na formação do grupo como na sua preparação para as entrevistas.

O questionário, composto de 78 perguntas abertas sobre os temas da paternidade, planejamento familiar, relação homem-mulher e trabalho da mulher, foi construído a partir de sugestões de todos os participantes, embora com inegável predominância dos que vinham se ocupando destes temas há mais tempo e com maior dedicação (as técnicas, mulheres).

A supervisão em grupo das entrevistas pré-testes serviu para reforçar a necessidade e a maneira de resumir as respostas sem "traduzi-las", regis- 
trando algumas das palavras usadas pelo respondente. Também foi frisado que a resposta "não sei” é tão válida como qualquer outra.

Os respondentes foram identificados por cada entrevistador dentro do seu círculo de conhecimentos, o que certamente contribuiu para a composição de uma amostra com membros de famílias mais estáveis (maritalmente, em termos de tempo de residência na favela $\mathrm{e}$, talvez, economicamente) dentro da heterogeneidade sempre existente. Um esforço foi feito, por cada entrevistador, de entrevistar um número igual de homens em três "condições reprodutivas": os que não tinham filhos ("filhos"); os que tinham filhos, mas não netos ("pais"); e os que tinham netos ("avós"). No total, foram entrevistados 130 homens.

$\mathrm{Na}$ análise dos dados, serão apresentadas as diferenças entre os grupos de idade ou condições reprodutivas quando a análise de qui quadrado $\left(\mathrm{x}^{2}\right)$ mostra $\mathrm{p}, 5$.

Em geral, reportamos somente as respostas mais freqüentes, incluindo as minoritárias quando estas remetem a atitudes mais tipicamente "tradicionais". Múltiplas respostas são possíveis.

Perfil dos Entrevistados $(N=130)$

\begin{tabular}{lclllr}
\hline Idade & $\%$ & $\begin{array}{l}\text { Condição } \\
\text { Reprodutiva }\end{array}$ & $\%$ & Estado Civil & $\%$ \\
\hline $18-25$ & 35 & filhos & 37 & casados & 51 \\
$26-50$ & 38 & pais & 34 & solteiros & 38 \\
+50 & 27 & avós & 29 & viúvos & 8 \\
& & & & separados & 2 \\
\hline Total & 100 & & 100 & & 100 \\
\hline
\end{tabular}

Idade variou entre 18 e 74 anos.

Idade média: 37 anos.

Tempo médio de residência na área: 19 anos.

Idade média ao começar a trabalhar: 13 anos $-71 \%$ na cidade e $28 \%$ na roça.

Idade média na $1^{3}$ relação sexual: 16 anos.

Idade média ao casar: 22 anos.

Idade média ao nascer $1^{\circ}$ filho: 23,4 anos.

Número médio de filhos: 2,66.

Tem filhos com apenas uma parceira: $85 \%$.

Solteiros com filhos: $11 \%$ dos solteiros atuais.

Tem INSS: $89 \%$. 


\section{Apresentação dos dados}

\section{Paternidade}

A maioria dos respondentes com filhos (73\%) afirmou que o seu primeiro filho foi fruto de uma gravidez desejada, enquanto uma minoria significativa $(26 \%)$ respondeu que essa gravidez não foi desejada. Apenas $50 \%$ declararam ter acompanhado a gravidez. Questionados sobre as dificuldades que os pais enfrentam no momento de o filho nascer, $52 \%$ da amostra se refere às dificuldades econômicas, enquanto $29 \%$ refere ao "nervoso" da espera durante o parto ou à sua exclusão do recinto médico. Sessenta e oito por cento já ouviram falar da licença paternidade, mas $89 \%$ consideram-na importante. As razões dadas, em $92 \%$ das respostas, reportam à atenção à mulher ou ao filho, ou à conveniência de ajudar nos afazeres domésticos. Apenas dois respondentes mencionaram o registro do filho, talvez a tarefa masculina mais tradicional desse momento. Noventa e cinco por cento da amostra acha importante o bebê tomar leite materno. Apenas $13 \%$ dos entrevistados com filhos afirmam que a mulher, em alguma gravidez, teve licença maternidade paga.

Na pergunta "Quais as dificuldades em fazer um bom Pré-Natal?" as respostas mais freqüentes foram: deficiências dos serviços de saúde $35 \%$; "não sabe" - $24 \%$; problemas financeiros - 14\%; falta de tempo $12 \%$.

A pergunta “A gravidez muda a vida do casal?" foi respondida na afirmativamente por $59 \%$ da amostra. Diferenças por condição reprodutiva mostram: "filhos" - 62\%; "pais" - 74\%; "avós" $-46 \%\left(\mathrm{X}^{2}=6,827 \mathrm{P}=\right.$ ,03). Dos que responderam que sim, $45 \%$ mencionaram maior responsabilidade ou seriedade; $16 \%$ colocaram que a vida do casal melhora de alguma forma; $14 \%$ afirmaram que o homem nessa situação assume mais os afazeres do lar; $13 \%$ disseram que o homem sai menos de casa; e $9 \%$ opinaram que a relação sexual é prejudicada ou que a atenção da mulher é dividida.

Sessenta e um por cento dos que têm filhos declararam que o seu modo de educar os filhos é parecido com a maneira que seus pais os educaram. Em resposta à pergunta "Como você vê a questão das brincadeiras sexuais entre as crianças?", $65 \%$ da amostra respondeu que isto é normal ou natural; $22 \%$ caracterizou negativamente; e $13 \%$ declarou que isto mostra falta de atenção adequada por parte dos pais.

Com respeito à dificuldade relativa de criar filhos homens ou filhas mulheres, $48 \%$ dos entrevistados acharam mais difícil criar filhas; $25 \%$ 
declararam que não há diferença; $17 \%$ consideraram mais difícil criar filhos homens; e um entrevistado respondeu que não é difícil criar filhos.

Em resposta à pergunta "Como é que você vê a questão da educação sexual dos filhos?", apenas um respondente diferenciou filhas e filhos, embora $8 \%$ tenham declarado que não sabiam responder. Setenta e três por cento dos entrevistados afirmaram que ambos, pai e mãe, devem ser responsáveis pela educação sexual dos filhos, e $65 \%$ se sentem preparados para isto. Análise por grupos de idade mostra que $51 \%$ dos que têm entre 18-25 anos; $65 \%$ entre $26-50$; e $83 \%$ dos com $+50\left(X^{2}=9,175 p=, 01\right)$ se sentem preparados, o que sugere alternativas intrigantes que os dados não permitem explorar - se é a experiência de vida que leva à sensação de estar preparado ou se a questão parece mais complexa para os mais jovens.

Em resposta à pergunta "Se você tivesse uma filha solteira que ficasse grávida, qual seria sua atitude?", 75\% da amostra indicou que aceitaria, apoiaria, perdoaria etc.; $37 \%$ afirmou também que procuraria o parceiro; e $18 \%$ afirmou "mandar embora, deixar ela resolver, reprimir ou obrigar a casar”. Três respondentes apontaram o aborto como solução.

\section{Planejamento familiar}

Para introduzir esta parte da entrevista, tivemos o cuidado de explicitar o assunto, em face do possível desconhecimento masculino: "Nessa parte, vamos ver algumas questões sobre o planejamento familiar. É fácil observar que hoje em dia o número de filhos tende a ser menor que antigamente".

A primeira pergunta "Você acha que as pessoas em geral têm condições de planejar o nascimento dos filhos?" foi respondida negativamente por $58 \%$ dos entrevistados; $66 \%$ destes apontaram dificuldades financeiras e $41 \%$ mencionaram falta de informação. Apenas três respondentes deram respostas do tipo "é Deus que planeja”, e três declararam que não sabiam.

Respostas à pergunta "Você já proibiu a gravidez de alguma parceira sua?", sugerida por um dos entrevistadores, parecem confirmar que esta é uma preocupação maior dos que ainda não têm filhos: respostas positivas foram dadas por $46 \%$ dos "filhos"; $23 \%$ dos "pais"; e $24 \%$ dos "avós" ( $\mathrm{X}^{2}$ $=6,941 \mathrm{p}=, 03)$. Ao mesmo tempo, todas as categorias afirmaram que nem sempre um filho é bem-vindo do ponto de vista do homem, o que é coerente com a declaração dos $26 \%$ que não desejaram a gravidez do seu primeiro filho. Cinqüenta e quatro por cento declararam que as mulheres não engra- 
vidam "para segurar o homem", enquanto $45 \%$ opinaram que, pelo menos às vezes, isto ocorre.

A partir da pergunta "Você conhece algum método para evitar filhos?", ficou evidente que nosso cuidado com a introdução do tema foi, no mínimo, exagerado: $95 \%$ declararam conhecer algum método. Com a necessária ressalva de que a laqueadura nem sempre é considerada como "método", os mais mencionados foram: pílula $-88 \%$; camisinha $-62 \%$; ligadura $28 \%$; DIU $-27 \%$; tabela $-26 \%$; diafragma $-13 \%$; vasectomia $-5 \%$. Sessenta e um por cento dos "pais", $42 \%$ dos "filhos" e $24 \%$ dos "avós" declararam que ele ou sua parceira utilizam, atualmente, algum método.

Perguntados sobre o melhor método, as respostas mais comuns foram: pílula $-36 \%$; ligadura $-20 \%$; camisinha $-15 \%$; tabela $-8 \%$; e vasectomia $-6 \%$. As razōes mencionadas mais freqüentemente foram: "mais prática, simples, menos trabalho" - 30\%; "mais seguro" - $26 \%$; "melhor para a saúde" - 18\%. Cinqüenta por cento dos respondentes afirmaram que o uso de métodos pode trazer algum problema, com diferenças significativas por condição reprodutiva: "filhos" - 58\%; "pais" $73 \%$; “avós” $-31 \%\left(\mathrm{X}^{2}=13,038 \mathrm{p}-, 001\right) ; 71 \%$ se referia a problemas de saúde; $15 \%$ a falhas ou rejeição do método; e dois respondentes mencionaram frigidez.

Quando perguntados especificamente sobre a ligadura ("O que você acha da ligadura de trompas?"), 58\% declararam ter uma visão positiva do método; $18 \%$ condicionaram o uso por idade ou fatores de saúde, ou opinaram que o mesmo tem vantagens e desvantagens; $17 \%$ colocaram apenas alguma desvantagem; e $6 \%$ afirmaram que não sabem. Setenta e dois por cento responderam positivamente à pergunta "Você permitiria a ligadura de trompas de sua parceira?" e proporção idêntica declarou que não faria vasectomia.

Em resposta à pergunta "Quem deve ser o responsável por evitar a gravidez?", 54\% apontaram "ambos"; 38\% disseram “a mulher"; e 5\% “o homem". Quinze por cento da amostra declarou que alguma parceira já recorreu ao aborto, e $22 \%$ afirmou que não sabe se isto aconteceu (índice elevado quando comparado com outras perguntas). Dos que declararam o aborto, $45 \%$ se reportaram a decorrentes problemas de saúde em resposta à pergunta "Isto criou alguma dificuldade para vocês?".

Respostas à pergunta "Você é contra ou a favor da legalização do aborto?" mostram $57 \%$ contra e $41 \%$ a favor. Análise das respostas favoráveis, por idade, aponta $57 \%$ dos que têm entre $18-25$ anos; $33 \%$ entre $26-50$; e $34 \%$ dos com $+50\left(\mathrm{X}^{2}=6,309 \mathrm{p}-.04\right)$. 


\section{Relação homem-mulher}

A pergunta "Na sua opinião, a questão da virgindade ainda tem importância?" foi respondida negativamente por $68 \%$ dos respondentes, mas $65 \%$ caracterizaram em termos negativos "Como você vê a liberdade sexual dos nossos tempos?". A pergunta "Na sua opinião, como deve reagir um homem diante da infidelidade?" (também sugestão de um dos membros masculinos da equipe de pesquisa) teve como resposta, em $48 \%$ dos casos, a separação; enquanto $12 \%$ acharam que "depende do caso"; $9 \%$ declararam não saber responder; e $20 \%$ não responderam, o maior índice de não-resposta de todas as perguntas.

A pergunta "As dificuldades financeiras atrapalham o bom relacionamento na família?" foi respondida afirmativamente em $71 \%$ dos casos, com diferenças significativas entre as condições reprodutivas: "filhos" $-60 \%$; "pais"-82\%; "avós" $-71 \%\left(\mathrm{X}^{2}=5,367 \mathrm{p}=.06\right)$.

“Como você vê a questão da igualdade entre homens e mulheres?" foi respondida, em $71 \%$ dos casos, como "normal, natural", ou "não tem, mas deveria existir", enquanto $29 \%$ se colocaram "contra" ou disseram que "não são iguais" (que pode nem sempre significar que não deveriam ser, na opinião do respondente). Análise destes $29 \%$ por condição reprodutiva mostra que $19 \%$ dos "filhos"; $24 \%$ dos "pais" e $49 \%$ dos "avós" deram essa resposta $\left(\mathrm{X}^{2}=9,270 \mathrm{p}=.01\right)$.

\section{Trabalho da mulher}

A pergunta "Como você vê a questão da mulher trabalhar fora?" foi respondida em termos positivos por $48 \%$ da amostra; $21 \%$ colocou que "é normal" ou "não acho nada"; $15 \%$ afirmou que "é uma necessidade"; $13 \%$ mencionou algum aspecto negativo; e $2 \%$ opinou que "aceito, mas só em caso de necessidade".

Em resposta à pergunta "Quais as vantagens e desvantagens de a mulher trabalhar fora?", $82 \%$ dos respondentes colocaram a vantagem financeira; e $18 \%$ opinaram que é melhor para a mulher. Nas desvantagens, $45 \%$ mencionaram desvantagens para a família; e $20 \%$ mencionaram o cansaço ou "divisão" da mulher. Apenas 5\% afirmaram que o marido é prejudicado, e $5 \%$ opinaram que o trabalho fora traz o perigo de a mulher "arrumar outro homem". Apenas um respondente opinou que "só tem desvantagem", assim como um colocou que "só tem vantagem". 
A pergunta a seguir, "Na sua opinião, a mulher trabalhar fora atrapalha a educação dos filhos?", foi respondida afirmativamente por $68 \%$ da amostra, com diferenças entre os grupos de idade: $56 \%$ dos que têm entre 18-25 anos; $76 \%$ entre $26-50 ;$ e $72 \%$ dos com $+50\left(\mathrm{X}^{2}=5,582 \mathrm{p}=, 061\right)$.

\section{Discussão}

Convém iniciar a discussão dos dados com algumas ressalvas de ordem metodológica, a partir da composição de uma amostra que não é, nem na sua dimensão, nem nos critérios de escolha, estatisticamente representativa da população de referência.

Com respeito aos entrevistadores, possíveis desvantagens da incorporação de pessoas "não profissionais" são contrabalançadas pela consideração de que eles são membros da comunidade estudada, além de serem do mesmo sexo/gênero dos entrevistados, o que minimiza a possibilidade de problemas de comunicação ou interpretação no processo de levantamento.

O uso de um questionário tem as reconhecidas vantagens e desvantagens do direcionamento extremo na abordagem dos tópicos. Aqui, um mínimo de proteção à visão do respondente foi tentado por meio da formulação de perguntas que deixassem em aberto, tanto quanto possível, a seleção dos elementos considerados relevantes pelo respondente.

Possível falta de correspondência entre "o que dizem" e "o que fazem" é dificuldade inerente a qualquer metodologia baseada em informação verbal. Neste caso particular, trabalhamos com a suposição de que o grau de identidade e proximidade social entre entrevistado e entrevistador ajudaria a evitar uma tendência a reportar "para inglês ver" ou mesmo "para mulher ver". Por outro lado, se é evidente que não podemos supor que o que é colocado como correto seja sempre refletido na prática, pelo menos temos uma indicação de que a afirmação de outros padrōes é, por algum motivo, de importância menor. Apontamos a existência de posições minoritárias que expressam claramente $o$ valor da dominação masculina ou dos velhos estereótipos.

Quanto aos dados, se considerarmos apenas as questões em que pelo menos $70 \%$ da amostra está de acordo, constataremos que os respondentes, em geral, declararam que a gravidez do primeiro filho foi desejada; que o bebê deve tomar leite materno; que a licença paternidade é importante para o homem poder dar atenção à mulher e ao filho e ajudar em casa; que pai e mãe são responsáveis pela educação sexual dos filhos e se sentem preparados para isto; que apoiariam uma filha solteira que engravidasse; que 
conhecem algum método para evitar filhos, principalmente a pílula e a camisinha; que permitiriam a laqueadura da sua parceira; que não fariam vasectomia; que as dificuldades financeiras atrapalham as relaçōes familiares; que a igualdade entre homem e mulher é normal ou natural; e que a maior vantagem da mulher trabalhar fora é a vantagem financeira.

Em relação às respostas em que pelo menos $50 \%$ da amostra concorda, constatamos que a maior dificuldade do pai no momento do filho nascer é a dificuldade financeira; que a gravidez muda a vida do casal; que o seu modo de educar os filhos é parecido com a maneira pela qual seus pais os educaram; que as brincadeiras sexuais entre crianças são vistas como normais; que as pessoas não têm condições de planejar o nascimento dos filhos por razões financeiras; que as mulheres não engravidam para "segurar" o homem; que o uso de métodos contraceptivos pode trazer algum problema; que a laqueadura é um bom método de contracepção; que ambos são responsáveis por evitar a gravidez; que o aborto nāo deve ser legalizado; que a questão da virgindade não é importante; que a liberdade sexual dos tempos atuais é negativa; que é positivo ou normal a mulher trabalhar fora, e que isto atrapalha a educação dos filhos.

$\mathrm{Na}$ tentativa de caracterizar a geraçāo mais nova, ou os homens que ainda não têm filhos, algumas diferenças significativas foram registradas, servindo para separar esta categoria das demais: os "filhos" se sentem menos preparados para a educaçāo sexual dos filhos, já proibiram a gravidez de alguma parceira, são a favor da legalização do aborto e têm uma visão mais positiva da questão da igualdade entre homem e mulher. Embora nāo ao nível de significância estatística, dão menos importância à virgindade, têm uma visão mais positiva da liberdade sexual atual $\mathrm{e}$ das brincadeiras sexuais entre as crianças, e acreditam menos que a mulher trabalhar fora atrapalha a educação dos fillhos.

Por outro lado, cssa categoria também se diferencia, relativamente, no sentido de declarar com maior freqüência que educam seus filhos de uma forma parecida à maneira que foram educados, acham que é mais difícil criar filhas mulheres, acreditam com maior freqüência que as mulheres engravidam para "segurar" o homem, declaram mais que é a mulher que deve ser a responsável por evitar a gravidez, e concordam menos que as dificuldades fin anceiras atrapalham o bom relacionamento na família.

\section{Considerações finais}

A separação das atividades de produção e de reprodução gerada pela revolução industrial firmou-se, no plano conceitual, como ponto de partida para 
a análise das questões de gênero, em um momento histórico em que seu reflexo espacial se mostrou extremo, com a produção organizada estabelecendo-se na esfera pública e a reprodução mantida na esfera privada. Dado que a mulher "ficou" com a reprodução e que o "seu" lugar perdeu as funções de produção, essa forma de organização pode ser interpretada como expressāo de uma maior distância social entre homens e mulheres.

É importante não esquecer que, apesar disso, a separação entre produção e reprodução, delimitada no plano conceitual, ultrapassa, ainda, o seu referente material, já que a produção e a reprodução estāo inexoravelmente vinculadas ao processo histórico de reprodução das sociedades e das vidas individuais.

A família como instituição histórica continua sendo um locus preponderante de articulação entre essas duas esferas, tanto material como ideologicamente: a família, para existir, teve sempre de se preocupar com as atividades de produção e de reprodução. Se, anteriormente, um aumento na produção familiar dependia também da reprodução de novos membros, agora esta reprodução é, no âmbito da família, cada vez mais dependente das atividades produtivas fora do lar.

Como instância mediadora, a família, coerente com os estereótipos históricos, esgota em primeiro lugar a força de trabalho dos adultos masculinos e, quando necessário, aciona a de outros membros. Na situação atual da família urbana de baixa renda no Brasil, que conta agora (mesmo que precarissimamente) com meios modernos de contracepção, e cujos novos membros não garantem um excedente econômico, o papel reprodutivo da mulher depende, cada vez mais, da sua própria participaçāo na esfera produtiva. Desta ótica, estamos diante de uma "transição de gênero".

Longe de serem fenômenos impulsionados a partir de opções, aspirações ou preferências ideológicas, tanto o controle da fecundidade como a participação feminina na esfera pública do trabalho representam requerimentos para a sobrevivência da unidade familiar, fato refletido na aceitaçāo dos homens do controle da fecundidade e na sua afirmação de que é positivo ou normal a mulher trabalhar fora. Entretanto, as condiçōes tanto do controle da fecundidade como do engajamento feminino no mercado de trabalho trazem conseqüências negativas sérias, principalmente para a mulher de baixa renda. Nesta situação, não seria surpreendente se as mulheres se conformassem menos com os novos requerimentos que os próprios homens.

A correspondência entre essas práticas sociais da população feminina de baixa renda e a ideologia feminista, que caracteriza a participação da mulher na esfera do trabalho e o acesso à contracepção e ao aborto como condições 
e indicadores de avanço na luta pela igualdade social dọ gêneros, é apenas aparente. Principalmente no contexto das condições materiais da população de baixa renda, essas mesmas práticas podem refletir um processo de reelaboração da desigualdade entre os gêneros, na medida em que significam novas obrigações sociais para a mulher, aceitas pelo homem. Mas esta própria aceitação, na dialética complexa da construção e reconstrução dos gêneros, se refletirá também no papel do homem, conforme as condições materiais.

Além das consequiências em termos de gênero, argumentamos no sentido da necessidade de se considerar que "os espaços, unidades e modalidades concretas da reprodução fazem parte integrante da luta de classes", ${ }^{24}$ e não somente pela contribuição do trabalho doméstico à reprodução da força de trabalho e, portanto, à produção e acumulação. Sem desconsiderar este fato estrutural, apontamos para a presença de relações de classe na esfera da reprodução: nas sociedades de maior desigualdade entre as classes, o trabalho dornéstico, sempre feminino, é assumido como trabalho (mal) remunerado pelas mulheres da classe dominada. Neste caso, a reprodução doméstica da força de trabalho é um fenômeno interclasse, fato encoberto pela concepção da esfera doméstica/familiar como espaço "não-capitalista" ou "pré-capitalista” onde as relações de classe não penetram. Ao contrário, análise dessa esfera revela não somente a presença de relações de classe, mas sua natureza antagônica.

Neste sentido, a inserção crescente da mulher de baixa renda no mercado de trabalho remunerado é um indicador da derrota da classe trabalhadora na sua luta por melhores salários. Na medida em que facilita o trabalho remunerado da mulher empregadora, é um dos mecanismos que garante as vantagens relativas desta classe na reprodução da sua força de trabalho, sua qualificação melhor e, portanto, a manutenção da desigualdade entre as classes. A ideologia da "nova mulher" que controla sua fecundidade e atua no mercado de trabalho remunerado normaliza e legitima a transformação, encobrindo não somente a reprodução da desigualdade de gênero, mas também a das classes sociais.

24. D. Combes e M. Haicault, "Produçāo e Reproduçāo, Relaçōes Sociais de Sexos e de Classes”, in A. Kartchevsky-Bulport et alli, O Sexo do Trabalho, Rio de Janeiro, Paz e Terra, 1987. 


\section{RESUMO}

Esfera de Reprodução em uma Visão Masculina:

Considerações sobre a Articulação da Produção e da Reprodução, de Classe e de Gênero

Este artigo aborda as transformações atuais na articulação entre as esferas de produção e de reprodução, e seu reflexo sobre a construção de gênero, considerando a família como instância mediadora. A partir da constatação de mudanças nas práticas sociais femininas, expressas no aumento das taxas de participação da mulher no mercado de trabalho e na queda brusca das taxas de fecundidade, o estudo propõe investigar o significado destas questões para um grupo de homens de baixa renda. O levantamento de dados foi baseado em uma metodologia participativa, que incorporou quatro homens das favelas de Manguinhos, Zona Norte da cidade do Rio de Janeiro, no processo de desenvolvimento do questionário e na aplicação do mesmo a 130 homens de três gerações nas suas comunidades. Concluímos que tanto o controle da fecundidade como a participação da mulher no mercado de trabalho são requerimentos para a sobrevivência familiar, já aceitas pelos homens como obrigações sociais da mulher - ou seja, estamos diante de um movimento histórico de "transição de gênero". Entretanto, essas práticas da população de baixa renda não podem ser interpretadas como avanços na igualdade social dos gêneros. Ao contrário, revelam uma relação entre a reelaboração da desigualdade de classe e de gênero.

\section{ABSTRACT \\ The Sphere of Reproduction from a Male Viewpoint: Considerations on the Interrelationships between Production and Reproduction, Class, and Gender}

The article addresses the question of current transformations in the interrelationships between the spheres of production and reproduction and their effects on the construction of gender, with the family considered a mediating factor. Female social practices have changed, as reflected in increased rates of female participation in the labor market and a sharp drop in the birth rate. This study investigates how one group of low-income men feels about these questions. Data collection was based on 
a participative methodology in which four men from the Manguinhos slums, on Rio's north side, took part in developing a survey and applying it to one hundred and thirty men from three generations within their community. It was concluded that both the control of fertility and female participation in the labor market are necessary to family survival and now accepted by men as a female social obligation - in other words, we are witnessing a historical movement of "gender transition". Nonetheless, these practices displayed by the low-income population cannot be interpreted as advances in the social equality of the sexes. On the contrary, they reveal a relation between the re-elaboration of class inequalities and gender inequalities.

\section{RÉSUMÉ}

Une Vision Masculine de la Sphère de Reproduction:

Considérations sur l'Articulation entre Production et Reproduction, Classe et Genre

Cet article aborde la question des transformations récentes de l'articulation entre les sphères de production et reproduction, et de ses effets sur la construction de genre, en considérant la famille comme instance médiatrice. A partir de la constatation des changements survenus dans les pratiques sociales féminines, exprimées dans l'augmentation des taux de participation des femmes au marché du travail et de la brusque cute du taux de fécondité, l'auteur propose de rechercher la signification de ces questions pour un groupe d'hommes de bas revenus. L'enquête de données fut réalisée suivant une méthodologie participante, incluant quatre hommes des favelles de Manguinhos, Zone Nord de la ville de Rio de Janeiro. Ils participèrent au processus d'élaboration de l'instrument d'enquête et à son application à 130 hommes de 3 générations, de leurs quartiers. Nous concluons qu'aussi bien le contrôle de la fécondité que la participation de la femme au marché du travail, sont des exigences pour la survie familiale, déjà reconnue par les hommes comme des obligations sociales de la femme - c'est-à-dire que nous sommes en présence d'une évolution historique de "transition de genre". Cependant, ces pratiques de la population de bas revenu, ne peuvent être interprétées comme des pogrès en matière d'égalité sociale des genres. Au contraire, elles révèlent unẹ relation entre la ré-élaboration de l'inégalité de classe et celle de genre. 